\title{
Estimating the Effect of Urban Density on Fuel Demand
}

\author{
Niovi Karathodorou \\ Daniel J. Graham \\ Centre for Transport Studies \\ Dept of Civil and Environmental Engineering \\ Imperial College London \\ London SW7 2AZ, UK \\ Robert B. Noland \\ Alan M. Voorhees Transportation Center \\ Edward J. Bloustein School of Planning and Public Policy \\ Rutgers University \\ New Brunswick, NJ 08901, USA \\ niovi.karathodorou05@imperial.ac.uk \\ d.j.graham@imperial.ac.uk \\ rnoland@rutgers.edu
}

Word count: 6300

\begin{abstract}
Much of the empirical literature on fuel demand presents estimates derived from national data which do not permit any explicit consideration of the spatial structure of the economy. Intuitively we would expect the degree of spatial concentration of activities to have a strong link with transport fuel consumption. The present paper addresses this theme by estimating a fuel demand model for urban areas to provide a direct estimate of the elasticity of demand with respect to urban density. Fuel demand per capita is decomposed into car stock per capita, fuel consumption per kilometre and annual distance driven per car per year. Urban density is found to affect fuel consumption, mostly through variations in the car stock and in the distances travelled, rather than through fuel consumption per kilometre.
\end{abstract}

Key words: urban density, fuel demand, elasticity, SURE 


\section{Introduction}

There is a substantial body of literature stretching back over many years that has sought to estimate the main determinants of fuel demand. For reviews of this literature see Graham and Glaister (2002a, 2002b), Goodwin (1992), Espey (1998), Hanly et al (2002) and Dahl \& Sterner (1991). This subject received a great deal of attention in the 1970s and 1980s when high fuel prices raised concerns about energy security. It is again a major issue as petroleum prices have reached new record highs and also as concerns over climate change have become more widely accepted. The transport sector accounts for a substantial proportion of global energy consumption and consequently climate change. This paper seeks to evaluate how urban density can affect the relative demand for road transport fuel, providing elasticity estimates that are sensitive to local accessibility patterns.

Figure 1 shows private transport energy consumption per capita against urban density based on data from the Millennium Cities Database for sustainable transport (1999). The graph indicates a negative relationship between transport fuel consumption and urban density. Such a relationship is supported by intuitive logic: in denser cities travel distances are often shorter, the share of walking and cycling trips tends to be larger and a compact public transport network becomes more viable allowing for alternatives to car usage.

The first work that examined these issues was that of Newman and Kenworthy (1989a,b). They collected cross-sectional data for 32 cities from Europe, Canada, Asia, Australia and the USA and calculated correlations between fuel consumption and density variables. They reported a strong negative correlation between fuel consumption per capita and urban density. Using fuel demand elasticities from the literature, they adjusted fuel consumption data for non-US cities to calculate the fuel consumption that would have occurred given US incomes, prices and vehicle efficiencies. They argued that the fact that the resulting fuel consumption data still exhibited some variation highlighted the role of urban density. The authors also argued that the relationship between fuel consumption and urban density is multiplicative and identified a threshold value for density at which, they believed, significant energy savings occurred. 
Figure 1: Private transport energy use per capita against urban density (Source: Millennium Cities Database for Sustainable Transport (1999))

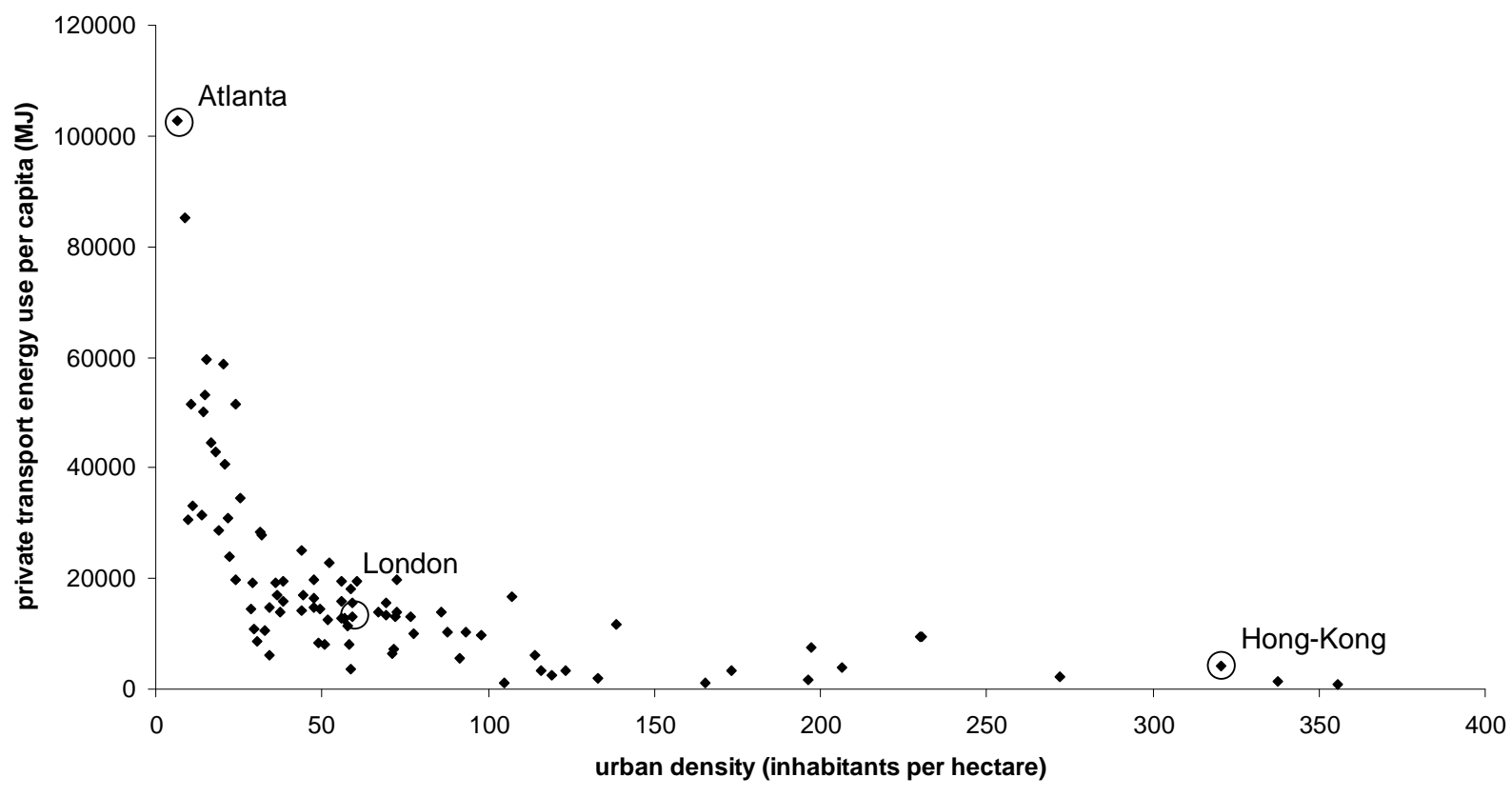

The key criticisms of Newman's and Kenworthy's work included the lack of control for variables known to affect fuel consumption such as gasoline price and income, and the lack of a complete multivariate analysis (Gomez-Ibanez, 1991, Mindali et al, 2004, Van de Coevering and Schwanen, 2006). Gomez-Ibanez (1991) argued that the lack of control for such variables made the existence of a threshold value for density questionable. Even when income and fuel price were taken into consideration (adjustment of gasoline consumption to reflect US prices and incomes), the indirect effects of income, such as its effects on density, were overlooked (Gomez-Ibanez, 1991). Other critiques tended to be more ideological, focussing on their policy conclusion that higher densities and public transport provision would reduce energy consumption (Gordon and Richardson, 1989).

Kenworthy and Laube (1999) attempted to address some of these concerns. Using the methodology of Newman and Kenworthy as a starting point, they collected a new dataset covering a larger set of cities that included additional variables such as GRP 
(Gross Regional Product) and car user costs. Newman's and Kenworthy's (1989a,b) studies had been criticised for using gasoline consumption instead of car use to investigate auto dependence. Thus, Kenworthy and Laube (1999) used car ownership, car use (average car kilometres per capita) and transit use (percent of total motorised passenger kilometres on transit) as dependent variables. Again using correlations, car user costs were found to be significantly correlated with car use, car ownership and transit use, after adjustments for wealth were made. GRP was found to be correlated with car use when all of the cities in the sample were taken into account, but not when only developed cities were considered. Finally, the correlations of urban density with car ownership, car use and transit use were found to be stronger than the corresponding correlations for GRP and car user costs.

The data from both studies have since been used by others to analyse fuel consumption or car dependence (e.g. Cameron et al 2003, Mindali et al 2004, Van de Covering and Schwansen 2006). Cameron et al (2003) defined an indicator of private motorised mobility to be the ratio of average private vehicle $\mathrm{km}$ per person per day over a theoretical maximum for an average daily trip length of $50 \mathrm{~km}$, and used dimensional analysis to model it. They concluded that private motorised mobility, and consequently private vehicle kilometres travelled, are mainly determined by urban structure. Mindali et al (2004) used the Co-Plot method to test the effect of urban density and land use mix on fuel consumption, but found no correlation between urban density and fuel consumption. Van de Covering and Schwanen (2006) supplemented the original data with data from other sources, to formulate econometric models for travel behaviour variables rather than fuel consumption. They estimated models for total annual distance by car per capita, total annual distance by public transport per capita, commuting distance, commuting time and the shares of commuting trips by car, by public transport and by walking/cycling. Urban density was found to be negatively correlated with total car distance and the share of the car for commuting trips, and positively correlated with the share of walking/cycling for commuting trips.

Van de Covering's and Schwanen's (2006) study is part of a wider literature on the travel behaviour effects, not only of urban density, but of other urban form characteristics such as land use mix or street design. Dependent variables that have 
been investigated in this literature include distances travelled (by mode), modal shares and mode choice. The survey by Boarnet and Crane (ch. 3, 2001) finds that the majority of studies show relationships between reduced car use and higher densities, mixed land-uses, or pedestrian friendly street design; but they also emphasise some shortcomings of the literature that could undermine the robustness of results.

Shim et al (2006) also conduct an investigation of the effect of density on fuel consumption. The authors use Korean city data to separately regress a number of urban form characteristics, including urban density, on gasoline consumption per car. They conclude that urban density is associated with reduced fuel consumption and suggest that high-density policies can be used as a tool to decrease transport energy use in Korean cities.

The literature discussed above has reported on analysis of various different dimensions of the relationship between urban density and patterns of travel and fuel demand. The link between urban density and the demand for fuel has, however, received little attention as a well-grounded economically plausible fuel demand model. There are some national or state level fuel demand analyses that have included population density or dummy variables to represent location or settlement type (e.g. Johansson and Schipper 1997, Greene 1982, Wheaton 1982, Puller and Greening 1999, Archibald and Gillingham 1980) ${ }^{1}$, but these studies have not constructed measures sufficient to enable direct estimation of the effect of urban density.

The purpose of this paper is to formally test the relationship between urban density and fuel demand and to explicitly estimate elasticities of fuel demand with respect to urban density. Typically, fuel demand models are based on national level, state level, and less frequently micro-level data ${ }^{2}$. In this paper we use aggregate city level data to represent urban density and we decompose urban fuel demand per capita as the product of car ownership per capita, fuel consumption per $\mathrm{km}$ and annual distance driven per car, with each component specified as a function of urban density. Models

\footnotetext{
${ }^{1}$ With the exception of Wheaton (1982) and Archibald and Gillingham (1980), who found statistically insignificant results, the authors have generally reported a negative effect of national/state population density or urban location on gasoline consumption.

${ }^{2}$ One exception is the study by Hirota and Poot (2005) which also used city level data, but their study was aimed at evaluating fuel demand responses to different car ownership taxes and usage, and their model did not have measures of urban form or density.
} 
for the three components are then estimated using cross-sectional data, both using ordinary least squares (OLS) and simultaneously in a seemingly unrelated regression equations (SURE) framework The results show that urban density does affect fuel consumption, mostly through variations in the car stock and in the distances travelled, rather than through fuel consumption per kilometre.

The paper is structured as follows. Section 2 discusses the explanatory variables considered and the model specification, including the choice of functional form and the choice of estimation method. Section 3 describes the data used for estimation. Results are then presented in section 4. Conclusions are drawn in the final section.

\section{Theory and model specification}

Following Wheaton (1982), Baltagi and Griffin (1983) and Johansson and Schipper (1997), the specification of fuel demand that we adopt in this paper decomposes consumption per capita as the product of car ownership per capita, fuel consumption per $\mathrm{km}$ and annual distance driven per car. This particular specification is attractive because it allows us to separately identify a number of distinct influences on demand. It also goes some way to address the difficulty associated with cross-sectional data in distinguishing short-run and long-run effects. The final elasticities derived can be interpreted as approximating long-run effects since we account for variation in the car stock and its composition as well as in the distances driven.

The model thus takes the following form:

$\mathrm{Q}=\mathrm{CAR} \cdot \mathrm{EFF} \cdot \mathrm{VKT}$

where

$\mathrm{CAR}=\mathrm{f}\left(\mathrm{PFUEL}, \mathrm{GDP}, \mathrm{Z}_{1}\right)$

$\mathrm{EFF}=\mathrm{f}\left(\mathrm{PFUEL}, \mathrm{GDP}, \mathrm{Z}_{2}\right)$

$\mathrm{VKT}=\mathrm{f}\left(\mathrm{PFUEL}, \mathrm{GDP}, \mathrm{CAR}, \mathrm{EFF}, \mathrm{Z}_{3}\right)$

and

\footnotetext{
${ }^{3}$ Baltagi and Griffin (1983) do not estimate models for all three components due to lack of data. Instead they estimate models for fuel consumption per car.
} 
Q is fuel consumption per capita, CAR is car ownership per capita, EFF is fuel consumption per kilometre (efficiency), VKT is car kilometres travelled per car per year, PFUEL is the price of fuel, GDP is the Metropolitan Gross Domestic Product per capita and $Z_{i}(i=1,2,3)$ are vectors of exogenous variables that include urban density.

The level of income and the price of fuel are of course included in all three models. Fuel consumption per $\mathrm{km}$ is included in the annual driving distance model as it determines, along with the price of fuel, the fuel cost of a car trip. Car ownership per capita is included to account for the fact that as the number of cars available to each person increases each car is used less. Urban density, our main focus here, was included in all three exogenous variable vectors. Our thinking on urban density is as follows.

i. Car ownership - we expect urban density to have a negative effect on car ownership because shorter distances in denser cities should reduce the need for a car. Furthermore, congestion and the limited availability of parking (or the cost of parking) in dense settlements could discourage potential car owners. Denser settlements can also sustain more compact public transport networks which can provide an alternative to the car (a variable for public transport density is explicitly included in the model, distinct from density).

ii. Fuel consumption per kilometre - fuel consumption per $\mathrm{km}$ can be affected through changes in the technological efficiency of cars or changes in driving habits. Higher densities can on the one hand influence the composition and consequently the fuel efficiency of the car stock (e.g.. parking limitations can encourage purchases of smaller cars), but on the other hand they can lead to less fuel-efficient 'stop and go' driving. Urban density could thus have countervailing effects on fuel consumption per $\mathrm{km}$ and we included it in the model to test not only whether it has an effect but the direction of this effect as well.

iii. Driving distance per car - urban density could affect driving distances because activities in denser cities are located with closer proximity so that trip 
lengths tend to be shorter. Shorter distances should increase the share of nonmotorised trips, resulting in reduced car usage. Furthermore, public transport networks are likely more extensive in denser cities which could lead to reduced car usage. However, we explicitly control for this by including a measure for public transport supply.

In addition to urban density, the following exogenous factors were also assumed to affect car ownership and the distances travelled by car.

i. Car ownership: Car user costs other than fuel could also influence potential car owners. Improved road provision should facilitate car travelling and could thus encourage car purchases. The supply of public transport should determine whether a feasible alternative to the car exists and could thus affect decisions on the need for a car.

ii. Distance driven per car: Car user costs, road supply and public transport supply could influence not only car purchases but also how much a car is used once it is purchased. All three were therefore included in the distance driven per car model as well. In addition, the cost of public transport to the user could possibly influence trade-offs between public transport and car usage.

Congestion could also affect both car ownership and the distances travelled, as well as fuel consumption per $\mathrm{km}$. Our data provide an 'average network speed' measure, which is 'the average speed of vehicles ( 7 day/24 hour average) on all classes of road in the metropolitan area'. Including this variable in the model we found it to be insignificant and it did not greatly affect the remaining results, although the elasticity of fuel consumption with respect to density was somewhat lower. This is largely unsurprising because congestion is both time and place specific, and as such, average network speed provides a rather crude proxy. Consequently, we did not include this variable in the final model.

Average trip distance (for all modes) was also included in the car ownership model to test the hypothesis that people travelling longer distances prefer to use the car and are thus more likely to purchase one. The trip variable was insignificant using OLS, but 
significant using SURE. Performing a likelihood ratio test between the restricted and unrestricted models, however, indicated no significant improvement in fit for both estimation methods. Furthermore, we found that the inclusion of average trip distance had no substantial effects on the other coefficients, indicating little effect from omitted variable bias. A key problem with the inclusion of this variable is that it must surely be endogenous; the need to travel longer might encourage car ownership, but also owning a car can result in more travel. For all the above reasons, we decided not to include average trip distance in the final model.

Regarding the choice of functional form, there is no a priori reason for supposing a specific functional form for equations (1), (2) and (3). The most common form used in the literature, particularly for cross-sectional models, is the log-log specification largely because it can reduce the potential for heteroskedasticity and because it gives direct estimates of the relevant elasticities. We performed an initial estimation of the system using the log-linear form and conducted RESET tests for functional misspecification. The RESET test was insignificant for the fuel consumption per $\mathrm{km}$ and the car kilometres travelled models, but significant for the car ownership per capita model indicating functional misspecification. Subsequently, a linear form was chosen for the car ownership model which passed the RESET test.

The three models were estimated both individually using ordinary least squares (OLS) and simultaneously using the seemingly unrelated regression equations method (SURE). SURE provides more efficient estimates than OLS when the error terms in different equations are contemporaneously correlated. Specific factors associated with each country that are not accounted for in the model, such as cultural influences or government policies, could give rise to contemporaneous correlation. On the other hand, the different functional forms of the equations could mean that such correlation may not exist. In fact, we conducted a Langragian multiplier test for the hypothesis that no correlation exists in errors across equations and we found this to be insignificant implying that OLS may be more efficient than SUR. However, the Langragian multiplier test is not definitive, especially for a small sample such as the one used in this analysis. We have thus included both an OLS and a SUR model in the results that follow, which is also useful for comparative purposes. 


\section{Data}

The models were estimated using cross-sectional data from the Millennium Cities Database for Sustainable Transport (1999) compiled by UITP. The database contains information on 100 cities from around the world for the year 1995. From these, 84 cities were used for the estimation of the model as data for some cities were incomplete. These 84 cities come from 42 different countries. A potential limitation of the Millennium Cities Database is that inconsistencies may exist in variable definitions and data collection procedures between the various countries included. Moreover, the cross-sectional nature of the data increases the potential for heteroscedasticity and omitted variable bias in regression modelling. That said, one of the guiding principles in establishing the Millennium Cities Database was to achieve a high level of data consistency. Furthermore, the problem we address in this paper requires a good range of variation in density, which is generally not available in timeseries data as density is highly persistent. We know of no panel data set with a sufficiently wide cross-section at the city level. Hirota and Poot (2005) have used the Millennium Cities Database along with data from other sources to estimate models of car ownership, vehicle kilometres travelled per capita, vehicle kilometres travelled per car and $\mathrm{CO}_{2}$ emissions per capita. Their study is however mostly aimed at evaluating the effects of acquisition, ownership and fuel taxes and does not include urban structure parameters. The results of the study compare well with previous literature. Other studies based on cross-sectional data are Wheaton (1982) and Drollas (1984).

To obtain the variation in urban density necessary to conduct our study it is extremely helpful to pool across cities from different countries. This can, however, introduce unobserved heterogeneity, for instance, because government policies can influence attitudes and behaviour towards transport. The inclusion of country specific dummies, is not possible in the present case because the data come from 42 different countries yet provide only 84 observations. Thus, the imposition of national fixed effects results in a considerable loss of degrees of freedom and effectively removes sampling variance in urban density. In fact, 28 countries have observations from just one single city.

We also ran the models with continent specific intercepts, but found the results difficult to interpret for two main reasons. First, the inclusion of continental dummies 
conditions our estimates on the mean for each continental group. For some of the key variables included in our model this led to insignificant and counter-intuitive results, largely because it again causes a substantial reduction in the sampling variance available for estimation. Essentially, the problem is that differences between the regions are already largely explained by variables such as density, GDP and fuel prices. Second, the choice of dummy variables can be regarded as somewhat arbitrary; continents are large and there may be no reason to believe that cities on the same continent, but in different countries, will exhibit some common element.

The Millennium Cities Database for Sustainable Transport (1999) contains direct data for car ownership per 1000 people, car kilometres travelled per car per year, the metropolitan gross domestic product per capita and urban density. Urban density (people per hectare) is measured for the urbanised zone of the metropolitan area, which excludes forest, farmland and large green spaces. The metropolitan area was defined as the catchment area for commuters. Since data were not necessarily available to match this definition, the administrative area that best corresponds to it was used ${ }^{4}$.

The Millennium Cities Database for Sustainable Transport (1999) contains data on the fuel consumption per $\mathrm{km}$ of private vehicles (i.e. cars, taxis and motorcycles), rather than cars. Car fuel consumption per km was estimated by assuming that taxis and cars have the same fuel consumption per $\mathrm{km}$, and that the ratio of motorcycle fuel consumption per $\mathrm{km}$ to car fuel consumption per $\mathrm{km}$ is for each of the following regions $^{5}$ :
OECD North America
0.44
OECD Europe
0.55

\footnotetext{
${ }^{4}$ It should be noted that the aggregate metropolitan density variable used in the study may not adequately represent the 'perceived' density experienced by the population, i.e. the density weighted by population to take into account the number of inhabitants that experience each density level. Moreover, aggregate metropolitan density could be more sensitive than perceived density to the metropolitan boundaries used for estimation. While recognising these limitations, data on perceived density are not available.

${ }^{5}$ These values are for the year 2000. The values were calculated using the 2000 reference values of the IEA/SMP Transport Model for the fuel consumption per $\mathrm{km}$ of two-wheelers and light duty vehicles. The spreadsheet containing the data is available at http://www.wbcsd.org/plugins/DocSearch/details.asp?type=DocDet\&ObjectId=MTE0Njc $\left(\right.$ accessed $6^{\text {th }}$ June 2008)
} 
OECD Pacific

Former Soviet Union

Eastern Europe

China

Other Asia

India

Middle East

Latin America

Africa
0.33

0.24

0.27

0.12

0.12

0.12

0.21

0.21

0.10

If $\mathrm{C}$ is the number of cars, $\mathrm{M}$ the number of motorcycles, $\mathrm{T}$ the number of taxis, $\mathrm{r}$ the ratio of motorcycle fuel consumption per $\mathrm{km}$ to car fuel consumption per $\mathrm{km}$ and $\mathrm{Ei}_{\mathrm{x}}$ the fuel consumption per $\mathrm{km}$ of vehicle type $\mathrm{x}$, then

$$
\begin{gathered}
\mathrm{Ei}_{\text {priv }}=\mathrm{Ei}_{\text {car }} \cdot \mathrm{C} /(\mathrm{C}+\mathrm{M}+\mathrm{T})+\mathrm{Ei}_{\text {taxi }} \cdot \mathrm{T} /(\mathrm{C}+\mathrm{M}+\mathrm{T})+\mathrm{Ei}_{\text {mot }} \cdot \mathrm{M} /(\mathrm{C}+\mathrm{M}+\mathrm{T}) \\
\mathrm{Ei}_{\text {priv }}=\mathrm{Ei}_{\text {car }} \cdot(\mathrm{T}+\mathrm{C}) /(\mathrm{C}+\mathrm{M}+\mathrm{T})+\mathrm{Ei}_{\mathrm{car}} \cdot \mathrm{r} \cdot \mathrm{M} /(\mathrm{C}+\mathrm{M}+\mathrm{T}) \\
\Rightarrow \mathrm{Ei}_{\text {car }}=\mathrm{Ei}_{\text {priv }} \cdot(\mathrm{C}+\mathrm{M}+\mathrm{T}) /(\mathrm{C}+\mathrm{T}+\mathrm{r} \cdot \mathrm{M})
\end{gathered}
$$

The car fuel consumption per $\mathrm{km}$ variable calculated using the above method was found to produce better fits than the original private vehicle fuel consumption per $\mathrm{km}$ variable.

The price of fuel variable used was calculated by dividing the price of fuel per $\mathrm{km}$, available in the database, by the energy use per private passenger vehicle kilometre.

Private vehicle ${ }^{6}$ costs were used as a proxy for car costs. The Millenium cities database contains data on private vehicle user cost per passenger kilometre, which includes, in addition to other costs, fuel costs. It was deemed useful to include in the model a car cost variable that does not incorporate fuel cost, so that fuel price can be included separately. This way not only did we avoid the assumption that fuel cost has the same elasticity as the remaining car costs, but also facilitated comparisons with the literature. To be able to deduct the fuel cost variable available in the Millenium Cities Database (fuel price per $\mathrm{km}$ ), the private vehicle user cost per passenger

\footnotetext{
${ }^{6}$ Private vehicles include cars, taxis and motorcycles.
} 
kilometre was converted to private vehicle user cost per vehicle kilometre assuming an average vehicle occupancy of 1.33 for all cities. Since the Millenium Cities Database (1999) contains no data on vehicle occupancy, the value was calculated using the Mobility in Cities database (2006) whose data refer to the year 2001. An average value was used for all cities as there is no exact match between the cities contained in the two databases. Finally, cost per vehicle kilometre was converted to cost per car by multiplying by the annual kilometres travelled per car. The cost variable calculated this way includes vehicle maintenance expenditure, insurance taxes, vehicle ownership taxes, expenditure on parking and tolls and vehicle depreciation. As the largest part of these costs does not change with the distance travelled, a measure representing variable rather than fixed costs would have been more appropriate for the annual distance driven per car model, but is unfortunately not available.

Road length per 1000 people was used to represent road provision and public transport seat-kilometre per capita was used to represent public transport supply. The average user cost of a public transport trip was used as a measure of public transport cost.

\section{Results}

The results for the car ownership, fuel consumption per $\mathrm{km}$ and annual distance driven models are given in Tables 1, 2 and 3 respectively. 
Table 1: Results for the car ownership per capita model (standard errors in parentheses)

\begin{tabular}{|c|c|c|c|c|}
\hline & \multicolumn{2}{|c|}{ OLS } & \multicolumn{2}{|c|}{ SURE } \\
\hline & coefficient & elasticity $^{1}$ & coefficient & elasticity $^{1}$ \\
\hline Constant & $\begin{array}{c}0.312 * * * \\
(0.0461)\end{array}$ & & $\begin{array}{c}0.332 * * * \\
(0.0441)\end{array}$ & \\
\hline Density & $\begin{array}{c}-0.000555 * * \\
(0.000182)\end{array}$ & -0.118 & $\begin{array}{c}-0.000582 * * * \\
(0.000173)\end{array}$ & -0.124 \\
\hline GDP & $\begin{array}{c}0.342 \times 10^{-5} * * * \\
\left(0.962 \times 10^{-6}\right)\end{array}$ & 0.212 & $\begin{array}{c}0.292 \times 10^{-5} * * \\
\left(0.921 \times 10^{-6}\right)\end{array}$ & 0.181 \\
\hline Fuel price & $\begin{array}{l}-0.00174 * \\
(0.000939)\end{array}$ & -0.039 & $\begin{array}{c}-0.00188 * * \\
(0.000893)\end{array}$ & -0.042 \\
\hline $\begin{array}{l}\text { Road length per } \\
1000 \text { people }\end{array}$ & $\begin{array}{c}0.306 \times 10^{-4} * * * \\
\left(0.541 \times 10^{-5}\right)\end{array}$ & 0.282 & $\begin{array}{c}0.296 \times 10^{-4} * * * \\
\left(0.514 \times 10^{-5}\right)\end{array}$ & 0.273 \\
\hline $\begin{array}{l}\text { Public transport } \\
\text { seat-km per capita }\end{array}$ & $\begin{array}{c}-0.127 \times 10^{-4} * * \\
\left(0.463 \times 10^{-5}\right)\end{array}$ & -0.125 & $\begin{array}{c}-0.119 \times 10^{-4} * * \\
\left(0.444 \times 10^{-5}\right)\end{array}$ & -0.116 \\
\hline $\begin{array}{l}\text { Car user cost per } \\
\text { car }\end{array}$ & $\begin{array}{c}-0.133 \times 10^{-7} * * \\
\left(0.461 \times 10^{-8}\right)\end{array}$ & -0.100 & $\begin{array}{c}-0.150 \times 10^{-7} * * * \\
\left(0.438 \times 10^{-8}\right)\end{array}$ & -0.113 \\
\hline $\mathrm{R}^{2}$ & 0.80 & & 0.79 & \\
\hline
\end{tabular}

1 elasticities are calculated at the point of means of the data

Note: $* * *=$ significant at 0.001 level, $* *=$ significant at 0.05 level, $*=$ significant at 0.1 level

Table 2: Results for the fuel consumption per $\mathrm{km}$ model (standard errors in parentheses)

\begin{tabular}{|l|c|c|}
\cline { 2 - 3 } \multicolumn{1}{c|}{} & OLS & SURE \\
\hline Constant & $\begin{array}{c}3.811 * * * \\
(0.325)\end{array}$ & $\begin{array}{c}3.808 * * * \\
(0.321)\end{array}$ \\
\hline Density & $\begin{array}{c}0.013 \\
(0.0269)\end{array}$ & $\begin{array}{c}0.013 \\
(0.0265)\end{array}$ \\
\hline FDP & $\begin{array}{c}-0.229 * * * \\
(0.0289)\end{array}$ & $\begin{array}{c}-0.228 * * * \\
(0.0286)\end{array}$ \\
\hline $\mathrm{R}^{2}$ & 0.44 & 0.44 \\
\hline
\end{tabular}

Note: $* * *=$ significant at 0.001 level, $* *=$ significant at 0.05 level, $*=$ significant at 0.1 level 
Table 3: Results for the annual distance driven per car model (standard errors in parentheses)

\begin{tabular}{|l|c|c|}
\cline { 2 - 3 } \multicolumn{1}{l|}{} & OLS & SURE \\
\hline Constant & $\begin{array}{c}4.528 * * \\
(1.881)\end{array}$ & $\begin{array}{c}5.053 * * \\
(1.753)\end{array}$ \\
\hline Density & $\begin{array}{c}-0.229 * * \\
(0.0905)\end{array}$ & $\begin{array}{c}-0.242 * * \\
(0.0840)\end{array}$ \\
\hline GDP & $\begin{array}{c}0.163 \\
(0.103)\end{array}$ & $\begin{array}{c}0.155 \\
(0.0954)\end{array}$ \\
\hline Fuel price & $-0.204 * *$ & $-0.178 * *$ \\
$(0.0898)$ & $(0.0834)$ \\
\hline Car ownership per & $-\begin{array}{c}-0.361 * * * \\
(0.0719)\end{array}$ & $\begin{array}{c}-0.275 * * * \\
(0.0668)\end{array}$ \\
\hline capita & $\begin{array}{c}-0.366 * \\
(0.189)\end{array}$ & $\begin{array}{c}-0.296 * \\
(0.175)\end{array}$ \\
\hline $\begin{array}{l}\text { Fuel consumption } \\
\text { per km }\end{array}$ & $\begin{array}{c}0.146 \\
(0.0928)\end{array}$ & $\begin{array}{c}0.090 \\
(0.0863)\end{array}$ \\
\hline Road length & $\begin{array}{c}0.0180 \\
(0.0500)\end{array}$ & $\begin{array}{c}-0.0189 \\
(0.0468)\end{array}$ \\
\hline $\begin{array}{l}\text { Public transport seat- } \\
\text { km per capita }\end{array}$ & $\begin{array}{c}-0.00507 \\
(0.0590)\end{array}$ & $\begin{array}{c}-0.0139 \\
(0.0545)\end{array}$ \\
\hline $\begin{array}{l}\text { Average user cost of } \\
\text { a public transport } \\
\text { trip }\end{array}$ & $\begin{array}{c}0.240 * * \\
\text { Car user cost per car }\end{array}$ & $\begin{array}{c}0.244 * * * \\
(0.0683)\end{array}$ \\
\hline R & $0.0727)$ \\
\hline
\end{tabular}

Note: $* * *=$ significant at 0.001 level, $* *=$ significant at 0.05 level, $*=$ significant at 0.1 level

In the car ownership model, the elasticity of urban density is significant and negative $(-0.12)$. It would seem that in denser cities car ownership is lower, perhaps because more activities can be reached on foot or by cycling. The negative elasticity could also reflect that the cost of parking in dense cities possibly discourages car ownership.

The elasticity of car ownership with respect to fuel price is very low (-0.039 with OLS, - 0.042 with SURE), but significant. The studies reviewed by Goodwin (1992) 
suggest values in the range -0.41 to -0.1 , with the exception of Mackett (1985) who suggests a value of -0.01 . Hirota and Poot (2005) quote from the literature the same values as Goodwin, but also cite Dargay and Vythoulkas (1999) who give elasticities in the range -0.18 to 0.36 . Johansson and Schipper (1997) suggest a value of -0.1 , again quite low. Wheaton (1982) on the other hand, finds no significant effect of fuel price on car ownership. Fuel price is more likely to affect the type of car owned rather than whether a car is owned or not and any changes in ownership take place in the long-run as it takes time for the car stock to be renewed. The low elasticity calculated in the present study might reflect the fact that the data used were not in price equilibrium and long-term effects were not captured by the static model.

The income elasticity is 0.21 with OLS and -0.18 with SURE. Graham and Glaister (2004) review short-term elasticities of car ownership with respect to income that fall in the range 0.24 to 0.34 , with a mean value of 0.28 . The long-run elasticities reviewed by the same authors fall in the range 0.3 to 1.1 with a mean value of 0.74 . Johansson and Schipper (1997) suggest a value of 1.00 for the long-run. Wheaton (1982), who used cross-sectional data, gives even higher values, in the range 1.375 to 1.89. Hirota and Poot (2005), who also use cross-sectional data at an urban level, give an estimate of 0.684 .

Car user costs are found to have a significant, although not very elastic effect on car ownership, which suggests that costs other than fuel play a role in decisions regarding car purchases. Road length is also found to have a significant effect on car ownership. The elasticity is positive ( 0.28 with OLS, 0.27 with SURE). This could reflect the impact of capacity on congestion in the sense that when travelling by car is made easier, more people decide to purchase a car. On the other hand, the coefficient of public transport seat-km per capita is negative, suggesting that provision of an extensive public transport network could reduce the need for a car.

Table 2 shows results from the fuel consumption per kilometre component of the model. It has been hypothesized that urban density can have competing effects on fuel consumption per $\mathrm{km}$. On one hand, parking issues in denser cities can lead to smaller, more fuel efficient cars. On the other hand, traffic conditions in denser cities can encourage 'stop and go' driving, which results in increased emissions. However, 
urban density was found not to have significant effects on the fuel consumption per $\mathrm{km}$, perhaps because density can affect fuel efficiency both ways.

The elasticity of fuel consumption per $\mathrm{km}$ with respect to income is -0.23 and highly significant with both estimation methods. This contrasts with Wheaton (1982) and Espey (1996), whose studies suggest a positive elasticity of fuel consumption per $\mathrm{km}$ with respect to income. Wheaton's (1982) and Espey's (1996) results could suggest that high incomes support larger and thus less fuel-efficient cars. On the other hand, a negative elasticity of fuel consumption per $\mathrm{km}$ with respect to income could indicate that income affects the age of the car stock; low incomes may result in older, less technologically advanced and thus less fuel-efficient, car stocks. Johansson and Schipper (1997) also derive negative income elasticities for fuel consumption per km (OLS long-run estimate -0.25). Both Espey (1996) and Johansson and Schipper (1997) also cite other studies that have suggested a negative estimate.

The elasticity of fuel consumption per $\mathrm{km}$ with respect to fuel price $(-0.24)$ is consistent with the literature. Johansson and Schipper (1997) suggest a long-run value of -0.4 . Wheaton (1982) gives estimates in the range -0.26 to -0.33 . Espey (1996) reviews studies that suggest values ranging from -0.06 in the short-run to -0.69 in the long-run. The negative elasticity could suggest that higher fuel prices lead to a lower fuel consumption per km, perhaps because people are adjusting their driving habits to reduce fuel consumption.

The results from the annual distance driven per car model, shown in table 3, suggest that urban density is negatively associated with the distances driven by car. The elasticity of annual distance driven per car with respect to urban density is -0.23 with OLS and -0.24 with SURE, and is significant at the 5\% level with both estimation methods. This may reflect the fact that denser cities allow people to travel shorter distances from one activity to another.

The results also suggest that the price of fuel is negatively associated with the annual distance driven per car. The elasticity is -0.20 with OLS and -0.18 with SURE. Johansson and Schipper (1997) suggest a value of -0.2. On the other hand, Wheaton's (1982) estimates are more elastic; he calculates elasticities in the range -0.500 to - 
0.547. Goodwin (1992) quotes a short-run elasticity of traffic levels with respect to fuel price of -0.16 and long-run estimates of -0.29 and -0.33 for cross-sectional and time-series studies respectively.

The elasticity of annual distance driven per car with respect to fuel consumption per $\mathrm{km}$,is -0.37 with OLS and -0.30 with SURE. It is significant at the $10 \%$ level for both estimation methods in contrast with Wheaton (1982). Fuel consumption per km determines, along with fuel price, the fuel cost of a trip. A negative coefficient could indicate that increased fuel consumption per $\mathrm{km}$ could discourage car travelling.

The elasticity of annual distance driven per car with respect to GDP is insignificant with both estimation methods, as in Hirota and Poot (2005). Wheaton (1982), on the other hand, derives significant elasticities (0.328 to 0.537). Johansson and Schipper (1997) suggest a value of 0.2. Road length per thousand people, public transport seat$\mathrm{km}$ per capita and the average user cost of a public transport trip were also found to be insignificant despite the hypothesis described in section 2 that they could all three affect people's driving decisions.

It is unsurprising that we find a negative elasticity of annual distance driven per car with respect to car stock per capita (-0.36 with OLS, -0.28 with SURE). It most likely reflects the fact that as car stock per capita increases, although the carkilometres driven in total might increase, the car-kilometres driven per car can decrease as each car, at least within a given household, is being used less. The elasticity was found to be highly significant. Wheaton (1982) also calculates significant negative elasticities, but his estimates are slightly more elastic ( -0.417 to 0.615). On the other hand, Johansson and Schipper's (1997) elasticities are mostly low and insignificant.

The positive elasticity of annual distance driven per car with respect to car costs should also not be surprising. Car user costs were included to account for differences in driving related to differences in car costs, other than fuel costs, between cities. However, as discussed in section two, the car cost variable included mostly fixed costs. Unfortunately, no variable separating variable costs was available. The positive 
coefficient could be seen as reflecting that when more is spent on a car, the more it is used. That is, those cities where people use cars more (for whatever reason) are also those cities where more expensive cars are purchased.

In order to decompose the overall elasticities of fuel consumption per capita with respect to a given variable $\mathrm{Z}$, the following calculations are done:

$\mathrm{Q}=\mathrm{CAR} \cdot \mathrm{EFF} \cdot \mathrm{VKT}$

$\Rightarrow \ln \mathrm{Q}=\ln (\mathrm{CAR} \cdot \mathrm{EFF} \cdot \mathrm{VKT})$

$=>\ln \mathrm{Q}=\ln \mathrm{CAR}+\ln \mathrm{EFF}+\ln \mathrm{VKT}$

$=>\partial \ln \mathrm{Q} / \partial \ln \mathrm{Z}=\partial \ln \mathrm{CAR} / \partial \ln \mathrm{Z}+\partial \ln \mathrm{EFF} / \partial \ln \mathrm{Z}+\partial \ln \mathrm{VKT} / \partial \ln \mathrm{Z}$

$=>\mathrm{e}_{\mathrm{Q}, Z}=\mathrm{e}_{\mathrm{CAR}, Z}+\mathrm{e}_{\mathrm{ENER}, Z}+\mathrm{e}_{\mathrm{VKT}, Z}$

where $\mathrm{e}_{\mathrm{Q}, \mathrm{Z}}$ denotes the elasticity of fuel consumption per capita with respect to $\mathrm{B}$.

The elasticities of fuel consumption per capita with respect to density, income and the price of fuel were thus calculated to be for each estimation method:

OLS: $\quad \mathrm{e}_{\mathrm{Q}, \mathrm{DENS}}=-0.118+(0.013)+(-0.229)=-0.334$

$\mathrm{e}_{\mathrm{Q}, \mathrm{GDP}}=0.212+(-0.229)+0.163=0.146$

$\mathrm{e}_{\mathrm{Q}, \mathrm{PFUEL}}=-0.039+(-0.242)+(-0.204)=-0.485$

SURE: $\mathrm{e}_{\mathrm{Q}, \mathrm{DENS}}=-0.124+(0.013)+(-0.242)=-0.353$

$$
\begin{aligned}
& \mathrm{e}_{\mathrm{Q}, \mathrm{GDP}}=0.181+(-0.228)+0.155=0.108 \\
& \mathrm{e}_{\mathrm{Q}, \mathrm{PFUEL}}=-0.042+(-0.243)+(-0.178)=-0.463
\end{aligned}
$$

where DENS denotes urban density.

The above results are summarised in the table below. It can be seen that they are reasonably robust to the estimation method used.

\begin{tabular}{|l|r|r|}
\cline { 2 - 3 } \multicolumn{1}{c|}{} & \multicolumn{1}{c|}{ OLS } & SURE \\
\hline Density & -0.33 & -0.35 \\
\hline GDP & 0.15 & 0.11 \\
\hline
\end{tabular}


The elasticity of fuel consumption with respect to GDP is very low in contrast with many results in the literature. Although both Graham and Glaister (2004) and Espey (1998) report very low values in their reviews, they also report elasticities higher than 2 and calculate a mean value for short-run income elasticities of 0.47 and long-run elasticities of 0.93 and 0.88 respectively. The present results contrast with Graham and Glaister's (2004) conclusion that fuel demand is heavily dependent on income. Wheaton (1984) and Drollas (1982) who use cross-sectional data also report an elastic income effect. Wheaton (1982) gives values in the range of 1.22 to 2.02. Drollas (1984) suggests an elasticity of 1.2, the same as Johansson and Schipper (1997) who use cross-sectional time-series data.

The elasticity of fuel consumption per capita with respect to fuel price is also lower than that given in other cross-sectional studies such as Wheaton (1982) and Drollas (1984) (-0.68 to -0.94 and -1.3 respectively) and in Johansson and Schipper (1997) ($0.70)$. However the range of values reported in the reviews by Graham and Glaister (2004) and Espey (1998) is large (-2.13 to 0.59 and -1.36 to 0 respectively for the short-run, and -22 to 0.85 and -2.72 to 0 respectively for the long-run) and the present results are within this range.

Our key result is the elasticity of fuel consumption per capita with respect to urban density. This is estimated to be -0.33 with OLS and -0.35 with SURE. The results suggest that urban density affects fuel consumption mostly through changes in the car stock and in the distances travelled by car. As discussed above, the effect on fuel consumption per $\mathrm{km}$ is very small. The elasticity of car ownership with respect to urban density is -0.12 and the elasticity of the annual distance driven per car with respect to urban density is in the range -0.23 to -0.24 . The effect of urban density on driving distance could represent more of a short-run effect, whereas the effect on car ownership could represent a long-run effect. If so, the value of $-0.33 /-0.35$ could represent a long-run elasticity and -0.23/-0.24 could represent a short-run elasticity. Johansson and Schipper (1997) suggest a long-run elasticity of -1.0 for fuel demand with respect to national population density. 


\section{Conclusions}

Elasticities of fuel demand with respect to urban density were estimated using a crosssectional urban level dataset. The benefit of using cross-sectional data is the greater variance in exogenous characteristics, compared to country-level time series analysis. In order to overcome the problem of ambiguity of the short or long-run character of estimates associated with cross-sectional data, fuel demand per capita was decomposed into car stock per capita, fuel consumption per $\mathrm{km}$ and annual distance driven per car. The overall elasticities calculated can be interpreted as long-run since not only the effects on driving, but also the effects on the car stock are accounted for.

Results suggest that urban density has an effect on fuel consumption. The elasticity of fuel consumption per capita with respect to urban density is estimated to be in the range -0.33 to -0.35 ; this is however less elastic than the long-run elasticity of fuel consumption with respect to national population density estimated by Johansson and Schipper (1997). Results suggest that urban density affects mainly the car stock and the distances travelled by car. The elasticity of car ownership with respect to urban density is -0.12 . The elasticity of the annual distance driven per car with respect to urban density is in the range -0.23 to -0.24 ; this could represent a short-run elasticity of fuel consumption with respect to urban density.

The effect of income on demand was calculated to be low in contrast with most studies that suggest fuel demand to be income elastic. Graham and Glaister (2004) reviewed elasticities as high as 1.71 in the short-run and 2.68 in the long-run. The effect of fuel price on fuel demand was estimated to be less elastic than in the national level cross-sectional studies by Wheaton (1982) and Drollas (1984). Results suggest that fuel price affects fuel demand mostly through variations in fuel consumption per $\mathrm{km}$ and driving distances rather than car ownership. This can either reflect that fuel price does not indeed affect demand for cars, but also that the cross-sectional dataset used was not in price equilibrium and the effect could not be captured by a static model.

\section{References}


Archibald, R. \& Gillingham, R. (1980) An Analysis of the Short-Run Consumer Demand for Gasoline Using Household Survey Data. The Review of Economics and Statistics, 62 (4), 622-628.

Baltagi, B.H \& Griffin, J.M. (1983) Gasoline Demand in the OECD: An application of Pooling and Testing Procedures. European Economic Review, 22, 117-137.

Boarnet, G.M. \& Crane, R. (2001) Studies of Urban Form and Travel. In: Boarnet, G.M. \& Crane, R. Travel by Design: The Influence of Urban Form on Travel. Oxford University Press, New York, pp. 33-59.

Blum, U., Foos, G. \& Gaudry, M. (1988) Aggregate Time Series Gasoline Demand Models: Review of the Literature and New evidence for West Germany. Transportation Research A, 22, 75-88.

Cameron, I., Kenworthy, J.R. \& Lyons, T.J. (2003) Understanding and Predicting Private Motorised Urban Mobility. Transportation Research D, 8, 267-283.

Dahl, C. \& Sterner, T. (1991) Analysing Gasoline Demand Elasticities: A Survey. Energy Economics, 13, 203-210.

Dargay, J. \& Vythoulkas, P. (1999), Estimation of a Dynamic Car Ownership Model: a Pseudo-Panel Approach. Journal of Transport Economics and Policy, 33, 287-302.

De Jong, G., \& Gunn, H. (2001) Recent Evidence on Car Cost and Time Elasticities of Travel Demand in Europe. Journal of Transport Economics and Policy, 35(2), 137-160.

Drollas, L.P. (1984) The Demand for Gasoline: Further Evidence. Energy Economics, $6(1), 71-82$.

Espey, M. (1996) Watching the Fuel Gauge: an International Model of Automobile Fuel Economy. Energy Economics, 18, 93-106. 
Espey, M. (1998) Gasoline Demand Revisited: an International Meta-Analysis of Elasticities, Energy Economics, 20, 273-295.

Gomez-Ibanez, J.A. (1991) A Global View of Automobile Dependence. Journal of the American Planning Association, 57 (3), 376-379.

Goodwin, P.B. (1992) A Review of New Demand Elasticities with Special Reference to Short and Long Run Effects of Price Changes. Journal of Transport Economics and Policy, 26, 155-163.

Gordon, P., Richardson, H.W. (1989) Gasoline Consumption and Cities: a Reply. Journal of the American Planning Association 55 (3), 342-347.

Graham, D. \& Glaister, S. (2002a) The Demand for Automobile Fuel: A Survey of Elasticities. Journal of Transport Economics and Policy, 36 (1), 1-26

Graham, D. \& Glaister, S. (2002b) Review of Income and Price Elasticities in the Demand for Road Traffic (London: Department for Transport).

Graham, D. \& Glaister, S. (2004) Road Traffic Demand Elasticity Estimates: A Review. Transport Reviews, 24 (3), 261-274.

Greene, D. (1982) State Level Stock System of Gasoline Demand. Transportation Research Record 801, 44-51.

Handy, S.L. (2005) Does the Built Environment Influence Physical Activity? Examining the Evidence. Critical Assesment of the Literature on the Relationships among Transportation, Land Use and Physical Activity. TRB Special Report 282. Available at http://trb.org/downloads/sr282papaers/sr282Handy.pdf, accessed on $15 / 01 / 08$.

Hanly, M., Dargay, J. \& Goodwin, P. (2002) Review of Income and Price Elasticities in the Demand for Road Traffic (London: Department for Transport). 
Hirota, K. \& Poot, J. (2005) Taxes and the Environmental Impact of Private Car Use: Evidence from 68 Cities. In: Reggiani, A. \& Schintler, L. (eds) Methods and Models in Transport and Telecommunications: Cross-Atlantic Perspectives. Springer Verlag: in press.

Johansson, O. \& Schipper, L. (1997) Measuring the Long-run Fuel Demand for Cars: Separate Estimations of Vehicle Stock, Mean Fuel consumption per km and Mean Annual Driving Distance. Journal of Transport Economics and Policy, 31, 277-292.

Kenworthy J.R. \& Laube F.B. (1999) Patterns of Automobile Dependence in Cities: an International Overview of Key Physical and Economic Dimensions with Some Implications for Urban Policy. Transportation Research A, 33, 691-723.

Mackett, R.L. (1985) Modelling the Impact of Rail Fare Increases. Transportation, 12 (4), 293-312.

Mindali, O., Raveh, A. \& Salomon, I. (2004) Urban Density and Energy Consumption: a New Look at Old Statistics. Transportation Research A, 38, 143-162.

Millennium Cities Database for Sustainable Transport (1999) [CD-ROM], Union Internationale des Transport Publique (UITP).

Mobility in Cities Database (2006) [CD-ROM], Union Internationale des Transport Publique (UITP).

Newman, P. \& Kenworthy, J.R. (1989a) Gasoline Consumption and Cities: A Comparison of US Cities in a Global Survey. Journal of the American Planning Association, 55 (1), 24-36.

Newman, P. \& Kenworthy, J.R. (1989b) Cities and Automobile Dependence: An International Sourcebook. Gower, Aldershot Hants UK.

Puller, S. \& Greening, L. (1999) Household Adjustment to Gasoline Price Change: an Analysis Using 9 Years of US Survey Data, Energy Economics, 21 (1), 37-52. 
Shim, G., Rhee, S., Ahn, K. \& Chung, S. (2006) The Relationship Between the Characteristics of Transportation Energy Consumption and Urban Form, Annals of Regional Science, 40 (2), 351-367.

Van de Coevering, P. \& Schwanen, T. (2006) Re-evaluating the Impact of Urban Form on Travel Patterns in Europe and North-America. Transport Policy, 13, 229239.

Wheaton, W.C. (1982) The Long-Run Structure of Transportation and Gasoline Demand. The Bell Journal of Economics, 13 (2), 439-454. 